\title{
The Pivotal Role of Thrombin in Cancer Biology and Tumorigenesis
}

\author{
Kristen M. Snyder, M.D., ${ }^{1}$ and Craig M. Kessler, M.D. ${ }^{1}$
}

\section{ABSTRACT}

The association of cancer and thrombosis has been known for nearly 150 years. Compared with patients without cancer, those with cancer have an increased risk of thrombosis and recurrent thrombosis. It is now well accepted that patients with idiopathic venous thromboembolism are also at increased risk of later being diagnosed with cancer. This is further confirmation of the intertwined nature of cancer and thrombosis. Although the mechanisms of this association are still under examination, much work has accrued over the past two decades to suggest an influence of thrombin on cancer biology. This review focuses on the important role of thrombin in cancer research; recent in vitro work illustrating the mechanisms by which thrombin may affect cancer angiogenesis, cell invasion, and enhanced tumor metastasis; and on clinical trials investigating the potential role of antithrombotics in cancer incidence and survival.

KEYWORDS: Cancer, thromboembolism, hypercoagulability, thrombin, antithrombotic

The connection between cancer and thrombosis was observed and described initially in the mid-19th century when Professor Armand Trousseau presented his observations to the New Sydenham Society in 1865. Professor Trousseau, being a very astute internist in Paris, was particularly impressed by the frequent occurrence of symptomatic migratory thrombophlebitis in his cancer patients, particularly those with gastrointestinal malignancies. It is the irony of medical history that he diagnosed his own thrombophlebitis and predicted his own death from gastric cancer. In fact, he died 6 months later with a gastroesophageal cancer, leaving us with a prescient eponymous syndrome that is ripe for exploitation intellectually, scientifically, and therapeutically.

Subsequently, in the modern era of clinical research, it is now appreciated that at least 10 to $20 \%$ of individuals who develop idiopathic venous thromboembolism (VTE) will develop evidence of cancer within

${ }^{1}$ Divisions of Pediatric and Adult Hematology-Oncology, Lombardi Comprehensive Cancer Center, Georgetown University Medical Center, Washington, DC.

Address for correspondence and reprint requests: Kristen $\mathrm{M}$. Snyder, M.D., Divisions of Pediatric and Adult HematologyOncology, Lombardi Comprehensive Cancer Center, Georgetown
2 years. ${ }^{1}$ The recent MEGA population-based casecontrol study revealed that cancer patients have sevenfold increased risk of developing venous thromboembolism over that of non-cancer patients. ${ }^{2}$ Interestingly, and pertinent to tumor biology, is the fact that these thrombotic complications occur most frequently in the first 3 months after diagnosis and are associated most commonly with those malignancies with distant metastases. ${ }^{2}$ Epidemiologic studies indicate that cancer patients have a threefold increased risk for recurrence over that of noncancer patients, and the death rate from cancer in the context of concurrent VTE is fourfold higher than that of cancer itself, and this increased likelihood of death rate is not related to the cancer or the VTE as independent risk factors. ${ }^{3}$ Although Trousseau hypothesized that VTE complications were more likely to occur with gastrointestinal (GI) adenocarcinomas, the assessment of hospital admissions actually indicates that the relative risk of

DC 2007 (e-mail: KMS121@gunet.georgetown.edu).

A Tribute to Eberhard F. Mammen, M.D. (1930-2008); Guest Editor, Emmanuel J. Favaloro, Ph.D., M.A.I.M.S.

Semin Thromb Hemost 2008;34:734-741. Copyright (C) 2008 by Thieme Medical Publishers, Inc., 333 Seventh Avenue, New York, NY 10001, USA. Tel: +1(212) 584-4662.

DOI 10.1055/s-0029-1145255. ISSN 0094-6176. 
VTE developing even in association with "liquid" hematologic malignancies ranged from 1.5 to 2.5 (compared with 4.5 -fold risk in pancreatic cancer). Further emphasizing the intrinsic pathobiology of malignant cells is the observation that VTE is the second most common cause of death in ambulatory cancer patients (tied with infection). ${ }^{4}$ These and many other observational analyses in the clinical setting have suggested repeatedly that cancer and coagulation are intertwined. The question remains whether the activation of coagulation affects the biology of the cancer and whether interfering with the coagulation process, either nonspecifically or via specific targeting of coagulation proteins, will alter the biology of the malignant cell.

These provocative issues stimulated Dr. Eberhard Mammen to collaborate closely with his colleague at Wayne State University, Dr. Kenneth Honn, who in the 1990s was investigating the effects of thrombin and its role in cancer cell growth and the mechanisms of tumor metastasis. Their article, published in the International Journal of Cancer in July 1993, demonstrated that tumor cell adhesion was dependent on the action of the native form of thrombin, alpha-thrombin. ${ }^{5}$ Specifically, alphathrombin increased the adhesion of tumor cells via upregulation of alpha IIb beta 3 integrin found on the surface of tumor cells. Conversely, tumor cell adhesion was impeded when the procoagulant property of thrombin was inhibited by the addition of hirudin and/or by blocking with antibodies against the alpha IIb beta 3 integrin. They believed the mechanism of thrombin's action was mediated by protein kinase $\mathrm{C}$ (PKC) because inhibitors of PKC also inhibited thrombin-enhanced adhesion. Further, they showed the importance of thrombin in an experimental model of metastasis by finding increased numbers of tumor colonies in the lung tissue of thrombintreated but not in that of control mice. ${ }^{5}$ These observations, in conjunction with the corroborative work of others, have provided important insights and have greatly contributed to what we now know today regarding the relationship of hemostasis and malignancy.

Thus, thrombin is appreciated as a central player in numerous aspects of cancer biology. Over the course of the past 15 to 20 years, much research has documented the importance of the effects of thrombin in cancer angiogenesis and metastasis. The net result of these research efforts and the importance of Mammen's observations are to solidify the concept that VTE is not just an epiphenomenon of cancer and that VTE itself may influence cancer biology. This review will focus on selected studies that illustrate the cancer-promoting effects of thrombin in vitro and on the results of selected recent clinical trials, which suggest that modulation of thrombin generation or the effects thereof in cancer patients could potentially alter the natural intrinsic course of cancer and could constitute the basis of novel therapeutic approaches.
The serum protease, thrombin, is generated after upregulation of the intrinsic coagulation pathway by the tissue factor-factor VIIa complex emanating from the extrinsic coagulation pathway (Fig. 1). Thrombin generation through the extrinsic pathway is limited substantially by the presence of tissue factor pathway inhibitor. Thrombin formation results in downstream procoagulant effects, including fibrin clot formation through the proteolytic cleavage of fibrinogen; fibrin clot stabilization via cross-linking mediated through activation of factor XIII (FXIIIa); preservation of thrombus integrity by activation of thrombinactivatable fibrinolysis inhibitor; perpetuation of the coagulation process through positive-feedback activation of coagulation factors XI, VIII, and V (further enhancing thrombin production by the intrinsic pathway); and activation of platelets via thrombin activation of protease-activated receptors (PAR 1 and 4 ) and platelet surface glycoprotein (GP) Ib-alpha on the platelet surface. ${ }^{6}$ Hemostasis is also promoted by thrombin cleavage of the von Willebrand factor protein-FVIII complex.

Under normal baseline conditions and in the absence of vascular insults, thrombin is bound to its specific inhibitor on the surface of endothelial cells, termed thrombomodulin. This complex is critical to the transformation of thrombin from a procoagulant into a modulating anticoagulant and contributes to the nonthrombogenic properties of the normal unperturbed endothelial surface of blood vessels. The thrombomodulin-thrombin complex activates protein $\mathrm{C}$, resulting in the formation of the activated protein $\mathrm{C}$-protein S complex and subsequent inactivation of FVIIIa and FVa, thereby damping down further thrombin generation and limiting procoagulant forces in vivo.

Importantly, the proteolytic effects of thrombin are not limited to the regulation of hemostasis alone. Further efforts have demonstrated its role in mitogenesis, ${ }^{7}$ proliferation of smooth muscle cells ${ }^{8-11}$ and fibroblasts, ${ }^{12}$ cellular adhesion, ${ }^{13-15}$ and cellular angiogenesis, invasion, and metastasis. ${ }^{5,16-19}$

\section{TUMOR CELL PROLIFERATION MEDIATED BY THROMBIN}

As early as the 1970s, investigators were able to demonstrate thrombin's potent mitogenic effects on chick embryo fibroblasts. ${ }^{7}$ More recent studies have demonstrated thrombin's role as a mitogen for vascular smooth muscle cells by activation of the nuclear factor kappa B $(\mathrm{NF}-\kappa \mathrm{B}) .{ }^{8}$ Others have shown enhanced proliferative effects on smooth muscle cells to be driven by thrombin-induced release of platelet-derived growth factor and basic fibroblastic growth factor. ${ }^{10}$ Human glioma cell lines were induced to proliferate by 


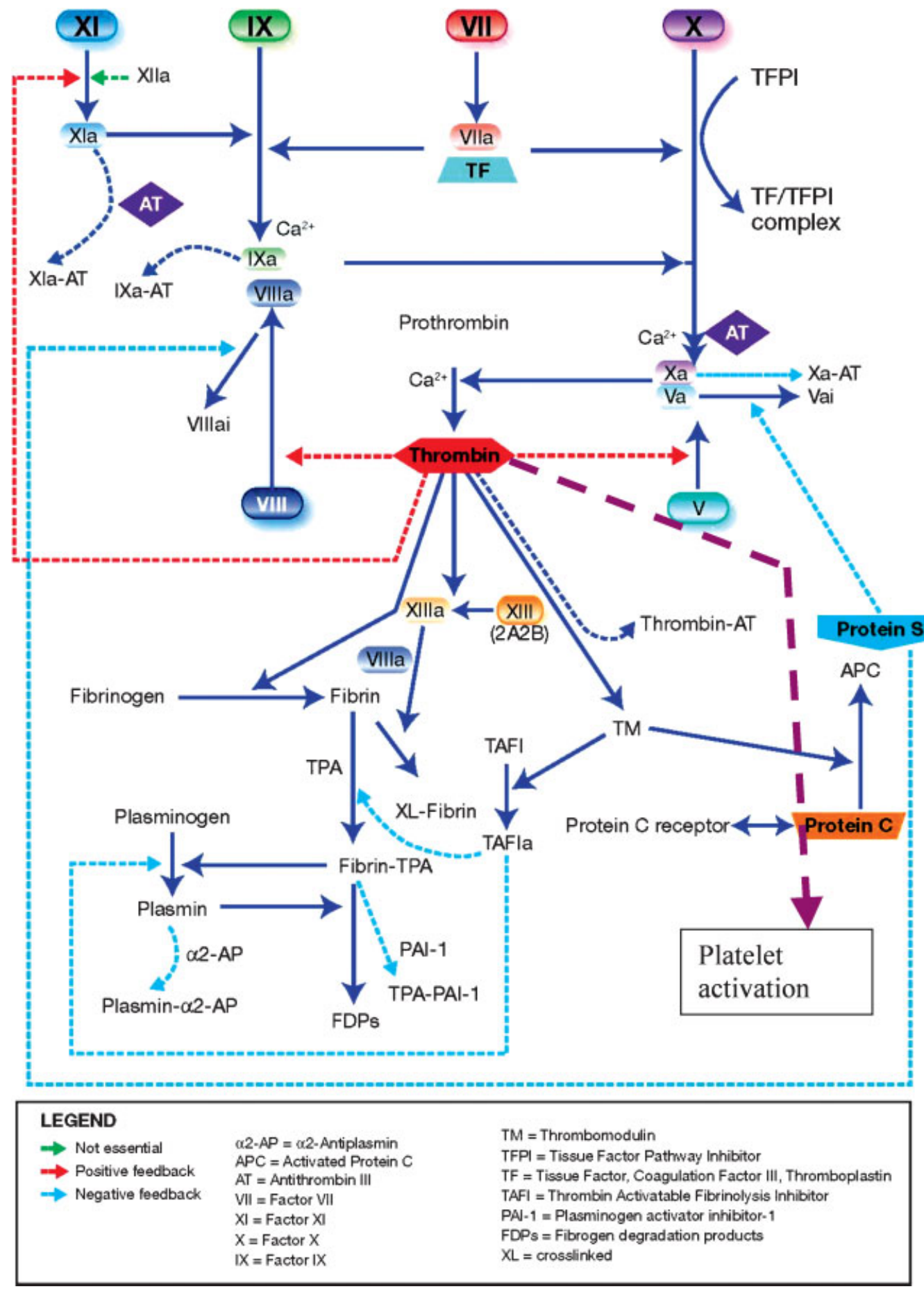

Figure 1 The coagulation cascade and the pivotal role of thrombin.

thrombin in a dose-dependent and bell-shaped fashion, and this proliferation was inhibited by addition of the specific thrombin inhibitor hirudin. Proliferation also occurred in the presence of coagulation factors II, V, X in combination with or without FVII. This was most likely thrombin mediated as the effects were inhibited by hirudin. ${ }^{20}$

\section{ROLE OF THROMBIN IN THE CRITICAL PROCESSES OF TUMOR CELL METASTASIS}

Successful tumor cell metastasis and survival are dependent on a complex series of steps, including tumor cell escape, invasion, attachment of cells to the extracellular matrix with subsequent proteolysis, homing and adhesion 
to a new site, translocation through the vasculature, and growth in a new environment. Thrombin has been linked to success in several steps of metastasis. As noted above, Mammen and Honn demonstrated the involvement of thrombin in adhesion via upregulation of tumor cell alpha IIb beta 3 integrin and found, using the experimental murine metastasis model, increased numbers of tumor cell colonies in the lung tissue of thrombin-treated but not control mice. ${ }^{5}$

Further recent work in vitro and ex vivo has also linked thrombin to each of the other steps of successful metastasis, including cell migration, ${ }^{21}$ adhesion, ${ }^{15}$ and tumor cell invasion. ${ }^{16}$ Finally, in an in vivo context, thrombin enhanced by up to 400 -fold tumor adhesion and metastasis in an experimental animal model. ${ }^{18}$ Fibrin formation (as well as PAR-1 activated platelets) protects metastatic cell tumor formation from natural killer (NK) cells, ${ }^{22-24}$ further perpetuating the proliferation and migration of tumor cell colonies.

To elaborate further, Kaufmann et al demonstrated that thrombin enhanced the migratory capacity of A-498 human renal carcinoma cells but had no effect on the proliferation of A-498 cells. ${ }^{21}$ This appeared to be mediated by thrombin activation of PKC, mitogenactivated protein kinases (MAP kinases), transcription factor NF- $\mathrm{KB}$, and $\mathrm{cAMP}$-dependent protein kinases (PKAs). ${ }^{21}$ This same group subsequently determined that both recombinant meizothrombin (an intermediate proteolytic enzymatic by-product generated during the conversion of prothrombin to thrombin in the coagulation cascade) and thrombin facilitated this function by "activating" calcium signaling in the renal cell carcinoma cells. The mechanism required the involvement of the PAR-1 and PAR-3 type thrombin receptors. ${ }^{25}$

Chiang et al noted that SW-480 human adenocarcinoma colon cells, incubated with concentrations of thrombin too low to proteolyze fibrinogen, exhibited enhanced adhesion to extra-cellular matrix (ECM) components (such as fibronectin) in vitro. This effect was reversed by the specific thrombin inhibitor hirudin and most likely mediated by thrombin's ability to upregulate tumor cell surface expression of beta 3 integrins. Antibeta 3 integrin antibodies blocked the enhanced adhesion, as did inhibition of PKC. Their data suggested that PKC inhibitors and/or rhodostomin, an Arg-Gly-Aspcontaining antiplatelet snake venom peptide that interferes with the binding of ECM constituents to the beta 3 integrins on the surface of SW-480 cells, could represent new approaches to the treatment of cancer, specifically by impeding thrombin-mediated metastatic potential. ${ }^{15}$ Their subsequent observations extended their insights into the tumor cell-coagulation connection. ${ }^{26}$ They noted that exposure of their SW-480 human colon adenocarcinoma cells to very low thrombin concentrations, as above, resulted in a rapid and significant increase in tissue factor (TF) mRNA expression, which was also dependent on the activation of PKC. The availability of increased $\mathrm{TF}$ in the tumor cells led to a 6.0-fold increase in their procoagulant activity in in vitro assays. Importantly, this thrombin-enhanced procoagulant activity was inhibited in the presence of hirudin and other potent serine protease inhibitors. The investigators hypothesized that the induction of $\mathrm{TF}$ expression in tumor cells by thrombin indicated that tumor-associated procoagulant activity might have a "positive-feedback effect" on in vivo local propagation of thrombus by thrombin formation.

Radjabi et al have examined the role of thrombin in tumor cell invasion as part of the process of metastasis. ${ }^{16}$ Incubation of U2-OS osteosarcoma cells with thrombin or PAR-1 thrombin receptor activating peptides stimulated the malignant cells to invade through a Matrigel (BD Biosciences, San Jose, CA) barrier in vitro; this phenomenon was inhibited by specific antibodies directed against matrix metalloproteinase (MMP)-9, a gelatinase important to the mechanism of tumor cell invasion. Invasion in this system was also blocked by the addition of an antibody, which prevented MMP-9 complex formation with beta 1 integrin. The investigators then demonstrated that thrombin upregulated the expression of MMP-9 mRNA and beta 1 integrin mRNA and that thrombin induced their coexpression on the tumor cell surface membrane to prime the cells for invasion.

Finally, experimental animal models have recently emerged that provide convincing confirmation that thrombin is involved in tumor cell metastasis in vivo. The Karpatkin laboratory has demonstrated that the preinfusion of thrombin into mice will enhance the metastasis of experimental lung cancer cells up to 400fold or up to 160-fold if the tumor cells are pretreated with thrombin in vitro prior to infusion into the murine model. ${ }^{18}$ Similar trends were noted in vitro and in vivo when thrombin receptor activation peptides were substituted for thrombin. Thrombin effects on the PAR-1 thrombin receptor on the surface of tumor cells appears to be concentration dependent with bimodal characteristics, so that thrombin enhanced tumor growth at low concentrations and impaired growth/apoptosis at higher concentrations. ${ }^{27}$ Closing the experimental loop, this laboratory has also demonstrated that thrombin induces the synthesis of tumor cell cathepsin D, which in turn mediates and stimulates tumor cell migration, tumor mass and volume growth, metastasis, and angiogenesis. ${ }^{19}$ Furthermore, MMP-9 was required to promote tumor cell-mediated angiogenesis. They and others have shown that thrombin plays a pivotal role in tumorassociated angiogenesis by upregulating the production of multiple vascular growth factors by tumor cells, including vascular endothelial growth factor (VEGF), angiopoietin-2, metalloproteinases 1 and 2, and inducing growth-related oncogene- $\alpha$ activity. 
Considering the collective information gained from in vitro studies and in vivo animal models, Karpatkin has asked the pivotal clinical question whether thrombin generated by tumor cells serves to preserve or awaken dormant tumor cells in humans, thus preventing host immune eradication, and whether the malignant phenotype and potential of tumor cells in humans are influenced by a procoagulant positive feedback axis, that is, tumor cells release TF to stimulate systemic coagulation and thrombin generation, which in turn promotes tumor growth and metastatic potential, angiogenesis, and systemic hypercoagulability. ${ }^{17}$

\section{HYPERCOAGULABILITY, THROMBOEMBOLISM, AND CANCER}

The association of venous and arterial thromboembolism and cancer is multifaceted. Malignancy may beget hypercoagulability and thrombosis as in Trousseau's syndrome, but it is also likely that hypercoagulability and thrombin generation may beget malignancy as in Karpatkin's hypothesis above. The annual incidence of VTE in cancer patients is approximately 1 in 250. Children with acute lymphoblastic leukemia have up to 500 times the risk of thrombus as that of the healthy pediatric population. ${ }^{28}$ Of all cancer patients, more than $15 \%$ will experience symptomatic VTE, up to $50 \%$ will have evidence of asymptomatic deep vein thrombosis/ pulmonary embolism (DVT/PE) if looked for, ${ }^{29}$ and more than $50 \%$ have VTE at autopsy. ${ }^{30}$ Further, patients with a diagnosis of cancer have an adjusted odds ratio of 53.5 of developing a VTE in the first 3 months after diagnosis of malignancy. ${ }^{2}$ According to the 8 th edition of the American College of Chest Physicians guidelines for VTE, patients with certain tumors of the brain, colon, or lung or with pancreatic, renal cell, or ovarian adenocarcinomas are at highest risk of developing primary and secondary VTE, and these patients should be considered to receive VTE prophylaxis. This is incontrovertibly established in the context of cancer surgery ${ }^{31}$ and is strongly recommended for those individuals at high risk for VTE who are receiving anti-angiogenic therapies for multiple myeloma (i.e., thalidomide and lenalidomide).Conversely, does the persistence of hypercoagulability and thrombin generation in vivo increase the risk of developing overt malignancy? Of patients with bilateral VTE, $26 \%$ will develop overt cancer within 2 years. ${ }^{1}$ Miller et al searched for an association between persistent activation of coagulation (thrombin generation in vivo) and development of cancer in the large male-populated Northwick Park Heart Study II. ${ }^{32}$ Nineteen percent of such individuals developed a cancer over 11 years of observation with $8.1 \%$ in the GI tract. Total mortality was almost twofold greater in those with persistent thrombin generation compared with those with normal background levels of coagulation (17.1\% vs. 9.7\%, $p<0.015)$, mainly due to all-cause cancer mortality $(11.3 \%$ vs. $5.1 \%, p<0.015)$ and GI cancer specifically (6.3\% vs. $1.9 \%, p<0.01) .^{32}$ They concluded that persistent activation of the coagulation cascade with thrombin generation may be important in the preclinical phases of tumorigenesis. Cancer developed approximately 3 times more frequently over the first year of follow-up after an idiopathic VTE in a Danish cohort. ${ }^{33}$ The investigators suggested that the malignancies were probably present but occult at the time of the VTE and that perhaps thrombin generated from the VTE was somehow important in the evolution of the preclinical cancer into overt disease. Cancers of the pancreas, ovary, liver and brain were the most commonly observed, and those younger than 60 years were at highest risk for cancer development.

Cancer-induced thrombosis results from complex interactions involving procoagulant characteristics of tumor cells, the endothelium, and the cellular environment. In normal physiologic states, the initiator of blood coagulation, TF, is sequestered from its ligand, FVII, until a triggering event (blood vessel injury or other changes in the endothelial cell surface) causes them to form the FVII-TF complex, which sets off the coagulation cascade and ultimately initiates thrombin and fibrin formation. TF expression appears to be robust in non-small cell lung cancer, ${ }^{34}$ colorectal cancer, ${ }^{35,36}$ breast cancer, ${ }^{37}$ hepatocellular carcinoma, ${ }^{38}$ and glioma cells. $^{20}$

Interference of the pathologic hypercoagulability mediated by TF-FVIIa in the host might be amenable to anticoagulation or direct antithrombin agents, which might prevent VTE and may also affect cancer incidence. In their study, Schulman and Lindmarker found retrospectively in patients with first episode of idiopathic DVT or PE without cancer at study entry a significantly lower occurrence rate of cancer in those who received 6 months of vitamin $\mathrm{K}$ anticoagulant therapy ( 45 of 435; $10.3 \%$ ) compared with that in those receiving 6 weeks of anticoagulant therapy (66 of 419; 15.8\%). These results were only noted after 2 years of follow-up, and there was no difference found in survival. However, there was a significant increase in the number of new urogenital cancers found in the group receiving anticoagulation for 6 months $(12 ; 2.8 \%)$ compared with that in the group receiving anticoagulation for 6 weeks $(28 ; 6.7 \%)$ $(p=0.01)$ when analyzed at 2 -year follow-up. ${ }^{39}$ Another multicenter, prospective study failed to show any difference in cancer incidence. In their study, Taliani et al evaluated the incidence of new cancer diagnosis after first episode of idiopathic VTE after either 3 months or 1 year of treatment with vitamin $\mathrm{K}$ antagonists up to 36 months after randomization. They found 13 of $210(6.2 \%)$ patients randomized to 3-month treatment compared with 19 of 219 (8.7\%) patients randomized to 1-year treatment were later diagnosed with cancer. 
Importantly, all patients diagnosed with cancer within the first 3 months of study were not randomized and therefore excluded from analysis. ${ }^{40}$ Hence, additional studies must be done to reliably prove a relationship between cancer incidence and anticoagulation with vitamin $\mathrm{K}$ antagonists.

Interest is accruing regarding the interactions of hemostasis and cancer and their influence on survival. Some studies have shown improved survival in patients with cancer receiving anticoagulation. Zacharski and colleagues published results of patients with lung, colon, head and neck, or prostate cancer receiving warfarin or placebo in addition to chemotherapy. They found no difference in survival. ${ }^{41}$ However, in those patients with small cell lung cancer (SCLC), the authors found those receiving warfarin in addition to chemotherapy had an increased median survival time (50 weeks vs. 24 weeks, $p=0.03) .{ }^{41,42}$ Although later studies in SCLC did not substantiate these results, they did suggest a benefit of warfarin use when added to chemotherapy or chemoradiotherapy regimens as demonstrated by improved tumor regression and increased disease-free survival ${ }^{43}$ and a statistically significant improvement in long-term survival. ${ }^{44}$ Given these results and the results of others, the effects of warfarin on cancer survival have yet to be answered. Further, it seems unlikely that future, formal clinical trials using warfarin will occur secondary to its limitations including its multiple drug interactions, oral dosing with emetogenic chemotherapy, and difficulties in maintaining consistent therapeutic levels.

Given the aforementioned shortcomings of Coumadin (Bristol Myers Squibb Co, Princeton, NJ) therapy in patients with cancer, Lebeau et al performed a multicenter clinical trial that randomized 277 patients with SCLC to either receive or not receive subcutaneous heparin injections for 5 weeks with chemotherapy. Those patients who received 5 weeks of subcutaneous heparin therapy in addition to chemotherapy obtained better complete response rates ( $37 \%$ vs. $23 \%, p=0.004$ ), better median survival ( 317 days vs. 261 days, $p=0.01$ ), and better survival rates at 1,2 , and 3 years ( $40 \%$ vs. $30 \%$, $11 \%$ vs. $9 \%$, and $9 \%$ vs. $6 \%$ ) compared with that in those patients with SCLC who received identical cancer treatment but did not receive heparin. ${ }^{45}$

The seminal CLOT study (Comparison of LowMolecular Weight Heparin Versus Oral Anticoagulant Therapy) was a prospective, randomized, open-label study in 676 patients with VTE and cancer that was designed to compare the relative efficacy and safety of low-molecular-weight heparin (dalteparin) in a secondary VTE prophylaxis regimen with that of vitamin $\mathrm{K}$ antagonists. There was a $52 \%$ reduction $(p<0.02)$ in recurrent VTE in the low-molecular-weight heparin (LMWH) arm compared with that in the oral anticoagulation arm after 5 months, but there was no difference in overall survival between the two arms. ${ }^{46}$ In a post hoc analysis, there was a statistically significant survival advantage in the LMWH group $(p=0.03)$ but only for those with nonmetastatic solid tumors. ${ }^{47}$

These results and others have prompted clinical investigation of the effects of LMWH on survival of patients with cancer. Moyano et al described the results of a prospective phase II trial evaluating chemotherapy and LMWH in patients with hormone-resistant prostate cancer. Investigators found a $50 \%$ prostate-specific antigen (PSA) response in 13 of 16 patients and a 75\% PSA reduction in 10 of 16 patients treated with this combination. ${ }^{48}$ Further results were reported by Icli et al who evaluated chemotherapy with or without LMWH (nandroparin) in patients with advanced pancreatic cancer. LMWH plus chemotherapy compared with chemotherapy alone improved tumor response rates $(64.7 \%$ vs. $12 \%, p=0.001$ ), median time to progression (6 months vs. 3 months, $p=0.0001$ ), overall median survival (9 months vs. 4 months, $p=0.0034$ ), and 1-year survival (47.7\% vs. $13.5 \%, p=0.029) .{ }^{49}$ Without overextrapolating the significance of these results, they do suggest that thrombin is intrinsically involved with cancer progression and provide the proof of principle to proceed with more definitive, prospective, large clinical trials to examine the potential antitumor effects of the LMWHs.

Similarly, investigators of the Fragmin Advanced Malignancy Outcome Study (FAMOUS) evaluated the effect of LMWHs on survival of a large number of patients with cancer but without thrombus. They randomized 385 patients with advanced solid tumors without thrombosis between the ages of 18 and 80 to receive dalteparin or placebo injection daily for 12 months. Results demonstrated a significantly higher survival in the dalteparin group at 2 and 3 years (78\% and $55 \%$, respectively) compared with that in the placebo group (60\% and $36 \%$, respectively) $(p=0.03)$.

\section{ROLE OF THROMBIN IN CANCER AND ANTITHROMBOTICS IN CANCER THERAPY: THE FULL CIRCLE}

If, as studies suggest, hemostasis plays an important role in cancer occurrence, angiogenesis, or metastasis, we must then ask "by what mechanism(s)?" We are again brought full circle back to the publication of Honn and Mammen, who, among others, have suggested that the pivotal role of thrombin in this process will become the therapeutic target of the future in cancer patients. The mechanisms by which thrombin may regulate tumor biology are still in their infancy. Recently published mechanisms of thrombin's role in cancer have demonstrated the upregulation of the thrombin receptor (PAR1) on various cancer cells, ${ }^{51-57}$ numerous pathways by which thrombin can regulate cell migration, ${ }^{21,54,58}$ the regulation of hepatocellular carcinoma migration, ${ }^{58}$ thrombin's involvement in cross-talk between tumor cells 
and the endothelium, ${ }^{59}$ its induction of MMP-9 mediating tumor cell invasion of osteosarcoma cells, ${ }^{16}$ upregulation of growth-regulated oncogene-alpha $(\mathrm{GRO}-\alpha)$ in various tumor cell lines, ${ }^{60}$ cleavage of the thrombin receptor PAR-1 by stromal-derived MMP-1 resulting in tumor cell migration and invasion, ${ }^{61}$ and induction of cathepsin D by thrombin and subsequent tumor cell migration, nodule growth, metastasis, and angiogenesis. ${ }^{19}$ This list is by no means inclusive but indicates where many of the challenges and opportunities lie.

\section{REFERENCES}

1. Bura A, Cailleux N, Bienvenu B, et al. Incidence and prognosis of cancer associated with bilateral venous thrombosis: a prospective study of 103 patients. J Thromb Haemost 2004;2:441-444

2. Blom JW, Doggen CJ, Osanto S, Rosendaal FR. Malignancies, prothrombotic mutations, and the risk of venous thrombosis. JAMA 2005;293:715-722

3. Levitan N, Dowlati A, Remick SC, et al. Rates of initial and recurrent thromboembolic disease among patients with malignancy versus those without malignancy. Risk analysis using Medicare claims data. Medicine (Baltimore) 1999;78: 285-291

4. Khorana AA, Francis CW, Culakova E, Kuderer NM, Lyman GH. Thromboembolism is a leading cause of death in cancer patients receiving outpatient chemotherapy. J Thromb Haemost 2007;5:632-634

5. Wojtukiewicz MZ, Tang DG, Ciarelli JJ, et al. Thrombin increases the metastatic potential of tumor cells. Int J Cancer 1993;54:793-806

6. Davie EW, Kulman JD. An overview of the structure and function of thrombin. Semin Thromb Hemost 2006;32 (Suppl 1):3-15

7. Chen LB, Buchanan JM. Mitogenic activity of blood components. I. Thrombin and prothrombin. Proc Natl Acad Sci U S A 1975;72:131-135

8. Maruyama I, Shigeta K, Miyahara H, et al. Thrombin activates NF-kappa $\mathrm{B}$ through thrombin receptor and results in proliferation of vascular smooth muscle cells: role of thrombin in atherosclerosis and restenosis. Ann N Y Acad Sci 1997;811:429-436

9. Dabbagh K, Laurent GJ, McAnulty RJ, Chambers RC. Thrombin stimulates smooth muscle cell procollagen synthesis and mRNA levels via a PAR-1 mediated mechanism. Thromb Haemost 1998;79:405-409

10. Cucina A, Borrelli V, Di Carlo A, et al. Thrombin induces production of growth factors from aortic smooth muscle cells. J Surg Res 1999;82:61-66

11. Fager G. Thrombin and proliferation of vascular smooth muscle cells. Circ Res 1995;77:645-650

12. Bruhn HD, Pohl J. Growth regulation of fibroblasts by thrombin, factor XIII and fibronectin. Klin Wochenschr 1981; 59:145-146

13. Szaba FM, Smiley ST. Roles for thrombin and fibrin(ogen) in cytokine/chemokine production and macrophage adhesion in vivo. Blood 2002;99:1053-1059

14. Sugama Y, Tiruppathi C, Offakidevi K, Andersen TT, Fenton JW 2nd, Malik AB. Thrombin-induced expression of endothelial $\mathrm{P}$-selectin and intercellular adhesion molecule-1: a mechanism for stabilizing neutrophil adhesion. J Cell Biol 1992;119:935-944

15. Chiang HS, Yang RS, Huang TF. Thrombin enhances the adhesion and migration of human colon adenocarcinoma cells via increased beta 3-integrin expression on the tumour cell surface and their inhibition by the snake venom peptide, rhodostomin. Br J Cancer 1996;73:902-908

16. Radjabi AR, Sawada K, Jagadeeswaran S, et al. Thrombin induces tumor invasion through the induction and association of matrix metalloproteinase- 9 and beta1-integrin on the cell surface. J Biol Chem 2008;283:2822-2834

17. Nierodzik ML, Karpatkin S. Thrombin induces tumor growth, metastasis, and angiogenesis: evidence for a thrombin-regulated dormant tumor phenotype. Cancer Cell 2006; 10:355-362

18. Nierodzik ML, Klepfish A, Karpatkin S. Role of platelets, thrombin, integrin IIb-IIIa, fibronectin and von Willebrand factor on tumor adhesion in vitro and metastasis in vivo. Thromb Haemost 1995;74:282-290

19. Hu L, Roth JM, Brooks P, Luty J, Karpatkin S. Thrombin up-regulates cathepsin D which enhances angiogenesis, growth, and metastasis. Cancer Res 2008;68:4666-4673

20. Ogiichi T, Hirashima Y, Nakamura S, Endo S, Kurimoto M, Takaku A. Tissue factor and cancer procoagulant expressed by glioma cells participate in their thrombin-mediated proliferation. J Neurooncol 2000;46:1-9

21. Kaufmann R, Junker U, Junker K, et al. The serine proteinase thrombin promotes migration of human renal carcinoma cells by a PKA-dependent mechanism. Cancer Lett 2002;180: 183-190

22. Palumbo JS, Talmage KE, Massari JV, et al. Platelets and fibrin(ogen) increase metastatic potential by impeding natural killer cell-mediated elimination of tumor cells. Blood 2005; 105:178-185

23. Palumbo JS, Talmage KE, Massari JV, et al. Tumor cellassociated tissue factor and circulating hemostatic factors cooperate to increase metastatic potential through natural killer cell-dependent and-independent mechanisms. Blood 2007; 110:133-141

24. Nieswandt B, Hafner M, Echtenacher B, Mannel DN. Lysis of tumor cells by natural killer cells in mice is impeded by platelets. Cancer Res 1999;59:1295-1300

25. Kaufmann R, Junker U, Schilli-Westermann M, Klotzer C, Scheele J, Junker K. Meizothrombin, an intermediate of prothrombin cleavage potently activates renal carcinoma cells by interaction with PAR-type thrombin receptors. Oncol Rep 2003;10:493-496

26. Chiang HS, Yang RS, Lin SW, Huang TF. Tissue factor activity of SW-480 human colon adenocarcinoma cells is modulated by thrombin and protein kinase $\mathrm{C}$ activation. $\mathrm{Br} \mathrm{J}$ Cancer 1998;78:1121-1127

27. Zain J, Huang YQ, Feng X, Nierodzik ML, Li JJ, Karpatkin $\mathrm{S}$. Concentration-dependent dual effect of thrombin on impaired growth/apoptosis or mitogenesis in tumor cells. Blood 2000;95:3133-3138

28. Athale UH, Chan AK. Thromboembolic complications in pediatric hematologic malignancies. Semin Thromb Hemost 2007;33:416-426

29. Johnson MJ, Walker ID, Sproule MW, Conkie J. Abnormal coagulation and deep venous thrombosis in patients with advanced cancer. Clin Lab Haematol 1999;21:51-54

30. Lee AY, Levine MN. Venous thromboembolism and cancer: risks and outcomes. Circulation 2003;107:I17-I21 
31. Geerts WH, Heit JA, Clagett GP, et al. Prevention of venous thromboembolism. Chest 2001;119:132S-175S

32. Miller GJ, Bauer KA, Howarth DJ, Cooper JA, Humphries $\mathrm{SE}$, Rosenberg RD. Increased incidence of neoplasia of the digestive tract in men with persistent activation of the coagulant pathway. J Thromb Haemost 2004;2:2107-2114

33. Sorensen HT, Mellemkjaer L, Steffensen FH, Olsen JH, Nielsen GL. The risk of a diagnosis of cancer after primary deep venous thrombosis or pulmonary embolism. N Engl J Med 1998;338:1169-1173

34. Goldin-Lang P, Tran QV, Fichtner I, et al. Tissue factor expression pattern in human non-small cell lung cancer tissues indicate increased blood thrombogenicity and tumor metastasis. Oncol Rep 2008;20:123-128

35. Seto S, Onodera H, Kaido T, et al. Tissue factor expression in human colorectal carcinoma: correlation with hepatic metastasis and impact on prognosis. Cancer 2000;88:295-301

36. Shigemori C, Wada H, Matsumoto K, Shiku H, Nakamura $\mathrm{S}$, Suzuki H. Tissue factor expression and metastatic potential of colorectal cancer. Thromb Haemost 1998;80: 894-898

37. Ueno T, Toi M, Koike M, Nakamura S, Tominaga T. Tissue factor expression in breast cancer tissues: its correlation with prognosis and plasma concentration. Br J Cancer 2000;83: 164-170

38. Poon RT, Lau CP, Ho JW, Yu WC, Fan ST, Wong J. Tissue factor expression correlates with tumor angiogenesis and invasiveness in human hepatocellular carcinoma. Clin Cancer Res 2003;9:5339-5345

39. Schulman S, Lindmarker P. Incidence of cancer after prophylaxis with warfarin against recurrent venous thromboembolism. Duration of Anticoagulation Trial. N Engl J Med 2000;342:1953-1958

40. Taliani MR, Agnelli G, Prandoni P, et al. Incidence of cancer after a first episode of idiopathic venous thromboembolism treated with 3 months or 1 year of oral anticoagulation. J Thromb Haemost 2003;1:1730-1733

41. Zacharski LR, Henderson WG, Rickles FR, et al. Effect of warfarin anticoagulation on survival in carcinoma of the lung, colon, head and neck, and prostate. Final report of VA Cooperative Study \#75. Cancer 1984;53:2046-2052

42. Zacharski LR, Henderson WG, Rickles FR, et al. Effect of warfarin on survival in small cell carcinoma of the lung. Veterans Administration Study No. 75. JAMA 1981;245: 831-835

43. Chahinian AP, Propert KJ, Ware JH, et al. A randomized trial of anticoagulation with warfarin and of alternating chemotherapy in extensive small-cell lung cancer by the Cancer and Leukemia Group B. J Clin Oncol 1989;7:993-1002

44. Maurer LH, Herndon JE II, Hollis DR, et al. Randomized trial of chemotherapy and radiation therapy with or without warfarin for limited-stage small-cell lung cancer: a Cancer and Leukemia Group B study. J Clin Oncol 1997;15:3378-3387

45. Lebeau B, Chastang C, Brechot JM, et al. Subcutaneous heparin treatment increases survival in small cell lung cancer. "Petites Cellules" Group. Cancer 1994;74:38-45

46. Lee AY, Levine MN, Baker RI, et al. Low-molecular-weight heparin versus a coumarin for the prevention of recurrent venous thromboembolism in patients with cancer. N Engl J Med 2003;349:146-153
47. Lee AY, Julian J, Levine M, et al. Impact of dalteparin lowmolecular-weight heparin (LMWH) on survival: results of a randomized trial in cancer patients with venous thromboembolism (VTE) [abstract]. Proc Am Soc Clin Oncol 2003;22:846

48. Moyano AJ, Gonzalez-Martin A, Fernandez E, et al. Weekly docetaxel (D) and short course of estramustine phosphate (EMP) with subcutaneous heparin low molecular weight in hormone resistant prostate cancer (HRPR): an active regimen without thrombosis related events [abstract]. Proc Am Soc Clin Oncol 2003;22:1751

49. Icli F, Akbulut H, Utkan G, et al. Low molecular weight heparin (LMWH) increases the efficacy of cisplatinum plus gemcitabine combination in advanced pancreatic cancer [abstract]. Proc Am Soc Clin Oncol 2003;22:1149

50. Kakkar AK, Levine MN, Kadziola Z, et al. Low molecular weight heparin, therapy with dalteparin, and survival in advanced cancer: the fragmin advanced malignancy outcome study (FAMOUS). J Clin Oncol 2004;22:1944-1948

51. Rudroff C, Striegler S, Schilli M, Scheele J. Thrombin enhances adhesion in pancreatic cancer in vitro through the activation of the thrombin receptor PAR 1. Eur J Surg Oncol 2001;27:472-476

52. Okamoto T, Nishibori M, Sawada K, et al. The effects of stimulating protease-activated receptor-1 and -2 in A172 human glioblastoma. J Neural Transm 2001;108: 125-140

53. Liu Y, Gilcrease MZ, Henderson Y, Yuan XH, Clayman GL, Chen Z. Expression of protease-activated receptor 1 in oral squamous cell carcinoma. Cancer Lett 2001;169: 173-180

54. Kaufmann R, Patt S, Zieger M, et al. The two-receptor system PAR-1/PAR-4 mediates alpha-thrombin-induced $[\mathrm{Ca}(2+)](\mathrm{i})$ mobilization in human astrocytoma cells. J Cancer Res Clin Oncol 2000;126:91-94

55. Kaufmann R, Patt S, Kraft R, et al. PAR 1-type thrombin receptors are involved in thrombin-induced calcium signaling in human meningioma cells. J Neurooncol 1999;42: 131-136

56. D'Andrea MR, Derian CK, Santulli RJ, Andrade-Gordon P. Differential expression of protease-activated receptors-1 and -2 in stromal fibroblasts of normal, benign, and malignant human tissues. Am J Pathol 2001;158:2031-2041

57. Bromberg ME, Bailly MA, Konigsberg WH. Role of protease-activated receptor 1 in tumor metastasis promoted by tissue factor. Thromb Haemost 2001;86:1210-1214

58. Kaufmann R, Rahn S, Pollrich K, et al. Thrombin-mediated hepatocellular carcinoma cell migration: cooperative action via proteinase-activated receptors 1 and 4. J Cell Physiol 2007;211:699-707

59. Goerge T, Barg A, Schnaeker EM, et al. Tumor-derived matrix metalloproteinase- 1 targets endothelial proteinaseactivated receptor 1 promoting endothelial cell activation. Cancer Res 2006;66:7766-7774

60. Caunt M, Hu L, Tang T, Brooks PC, Ibrahim S, Karpatkin S. Growth-regulated oncogene is pivotal in thrombininduced angiogenesis. Cancer Res 2006;66:4125-4132

61. Pei D. Matrix metalloproteinases target protease-activated receptors on the tumor cell surface. Cancer Cell 2005;7:207208 